\title{
Solanum nigrum Ethanolic Extract (SNE) Increases Cytotoxic Activity of Doxorubicin on MCF-7 Cell
}

\author{
Dyaningtyas Dewi Pamungkas Putri ${ }^{1,2^{*}}$, Erlina Rivanti ${ }^{2}$, Raditya Prima Istiaji ${ }^{2}$, Edy Meiyanto ${ }^{2}$ \\ 'Pharmacology laboratory, Departemen Pharmacology and Clinical Pharmacy, Universitas Gadjah Mada, Yogyakarta \\ ${ }^{2}$ Cancer Chemoprevention Research Center, Faculty of Pharmacy Universitas Gadjah Mada,Yogyakarta
}

\begin{abstract}
Leunca (Solanum nigrum L.) is a potential source of natural anticancer agents. Solanum nigrum L. ethanolic extract (SNE) has cytotoxic activity in several cancer cell lines. We aimed to evaluate the ability of SNE to increase MCF-7 cell sensitivity to doxorubicin as a chemotherapeutic agent for breast cancer. Cell viability of SNE and its combination treatment with doxorubicin were conducted by 3-(4,5-dimethylthiazol-2-yl)-2.5-diphenyltetrazolium bromide (MTT) assay, and apoptosis assay was analyzed by Ethidium bromide-acridine orange method. The SNE showed a cytotoxic effect in the MCF-7 cell line with IC $\mathrm{C}_{50} 50 \mu \mathrm{g} / \mathrm{mL}$. Combination treated DOX-SNE resulted in a combination index $(\mathrm{Cl})$ value of 0.21 , indicating strong synergism SNE and doxorubicin. The SNE $25 \mu \mathrm{g} / \mathrm{mL}$ combined with doxorubicin 100 nM optimally induced apoptosis of MCF-7 cells. We concluded that SNE is the potential to be developed as a co-chemotherapeutic agent through apoptosis induction though the molecular mechanism need to explore.
\end{abstract}

Keywords: Solanum nigrum L. herb ethanolic extract, doxorubicin, MCF-7, apoptosis.

\section{INTRODUCTION}

Abnormal cell proliferation leads the cancer cells. Cancer cells grow, divide uncontrolled, invade, and spread throughout the body (Cooper and Hausman, 2020). Breast cancer is the most common cancer-causing mortality in women and is the most common cancer in the world (Heer, et al., 2020). Overexpression of receptor estrogen, progesterone receptor, and human epidermal growth factor receptor 2 (HER2) are biomarker for breast cancer prognosis (Ulaner, et al., 2016). Hormonal therapy such as hormone replacement therapy (HRT) for postmenopausal, ovulation-stimulating medications, contraceptive pills increase the risk factor of developing breast cancer. Otherwise, the lifestyles such as alcohol consumption, diet, and smoking improve breast cancer risk (Momenimovahed and Salehiniya, 2019).

Therapy for breast cancer depends on the stage/stadium of the pathology and development of cancer cells. The main goals of therapy breast cancer are inhibiting cell proliferation or decreasing cancer cells' metastatic incidence, and prolonging patient life. Chemotherapy agents such

Submitted: April 23, 2020

Revised: June 2, 2020

Accepted: January 5, 2021

*Corresponding author: dyaningtyas.dewi.p.p@ugm.ac.id 
as tamoxifen, anthracycline, 5-Fluorouracil are recommended and common in non- and metastatic breast cancer types (Wang, et al., 2018; Waks and Winer, 2019; Jouybari, et al., 2019). Doxorubicin (DOX) has been used for decades and has been modified to increase therapy effectiveness (Lankelma, et al., 1999; Franco and Ait-Oudhia, 2018; Ansari, et al., 2017). However, using high concentrations of DOX or prolonged time will cause drug resistance. So, to prevent the resistance of DOX is increasing the ability and effectiveness of doxorubicin. Based on several researches, combination with natural compound that has cytotoxic activity in cancer cells effectively improves the potency of DOX.

Leunca (Solanum nigrum L.) is a Solanaceae family. The active compounds of $S$. nigrum are glycoalkaloids, polyphenolic, polysaccharide, and glycoprotein, solanine, solasodine, and solamargine. Based on previous research, Solanum nigrum L. has cytotoxic activity on cancer cells by inducing apoptosis, G2/M cell cycle arrest, and autophagy (Elbehairi, et al 2020; Butt, et al., 2018; Ling, et al., 2019; Shirkavad, et al., 2019). The combination treatment of Leunca with chemotherapy agent increases the chemotherapy's sensitivity in vitro and reduces the toxicity in vivo (Sarmoko, et al., 2011; Maruti, et al.,2011; Rumiyati, et al., 2015). Co-chemotherapy increased the chemotherapeutic efficacy and reduced the resistance evidence on chemotherapy, allowing chemotherapy on the lower dosage of a chemotherapy agent that use for therapy.

This research aimed to investigate the potency of Solanum nigrum L. ethanolic extract (SNE) on MCF-7 breast cancer cells. The effectiveness of the combination of chemotherapy agents with SNE was observed to investigate the activity of SNE through increasing the cytotoxicity of DOX on MCF-7 cells, allowing the use of lower concentrations of SNE and DOX. The possible mechanism on the toxicity of SNE and DOX were observed through apoptosis evidence.

\section{MATERIALS AND METHODS}

\section{Sample Preparation}

Dried powder of Solanum nigrum L. obtained from Balai Besar Penelitian dan Pengembangan Tanaman Obat dan Obat Tradisional (B2P2TOOT), Indonesia. The dried powder of Solanum nigrum L. was extracted in $95 \%$ ethanol for 7 days. The SNE was concentrated under a vacuum rotary evaporator.

\section{Cells Lines}

MCF-7 cell lines were provided by Prof. Tatsuo Takeya (Nara Institute of Science and Technology, Nara, Japan). The cells were cultured in complete medium culture consist of Dulbecco's Modified Eagle Medium (DMEM) (Gibco, New York, USA), 10\%v/v Fetal Bovine Serum (FBS) (Gibco), and 1\% Penicillin- Streptomycin (Gibco) at the temperature of $37^{\circ} \mathrm{C}$ and with a flow of $5 \%$ $\mathrm{CO}_{2}$.

\section{Drugs}

Doxorubicin (DOX) (Ebewe vial $10 \mathrm{mg} / 5$ $\mathrm{mL}$ ) purchased from PT. Ferron Par Pharmaceutical (Cikarang, Indonesia) was diluted directly in a culture medium.

\section{Single and Combination Cytotoxic Assay}

The cytotoxic assay was measured using MTT method. MCF-7 cells were adjusted to $5 \times 10^{3}$ cells/well and cultured in $100 \mu \mathrm{L}$ culture medium in 96 well plates and then incubated one day. The cells were treated with various concentrations of SNE (1-80 $\mu \mathrm{g} / \mathrm{mL})$ and various concentrations of DOX (0.25-0.8 $\mu \mathrm{M})$. After $24 \mathrm{~h}$ incubation, MTT reagent was applied, followed by $4 \mathrm{~h}$ incubation. $10 \% \mathrm{v} / \mathrm{v}$ SDS in $0.1 \mathrm{~N} \mathrm{HCl}$ as stopper reagent was then applied. The plate was then kept with protection from light overnight, continued with absorbance determination $(\lambda 595 \mathrm{~nm})$ using ELISA reader (Bio-Rad, Hercules, California, USA). The absor- 
bance was used to calculate $\mathrm{IC}_{50}$ value, which is the concentration inhibiting $50 \%$ of cell growth. To investigate whether SNE increases the sensitivity of DOX, SNE was treated in combination with DOX. Combinational treatment was evaluated by calculating Combination Index (CI) value (Reynolds and Maurer, 2005):

$$
C l=D_{1} / D_{x 1}+D_{2} / D_{x 2}
$$

$\mathrm{D}_{1}$ and $\mathrm{D}_{2}$ represent concentrations used in combinational treatment, while $\mathrm{D}_{\mathrm{x} 1}$ and $\mathrm{D}_{\mathrm{x} 2}$ are single treatment concentration giving the same response as $\mathrm{D}_{1}$ and $\mathrm{D}_{2}$, respectively. $\mathrm{CI}$ value represents the

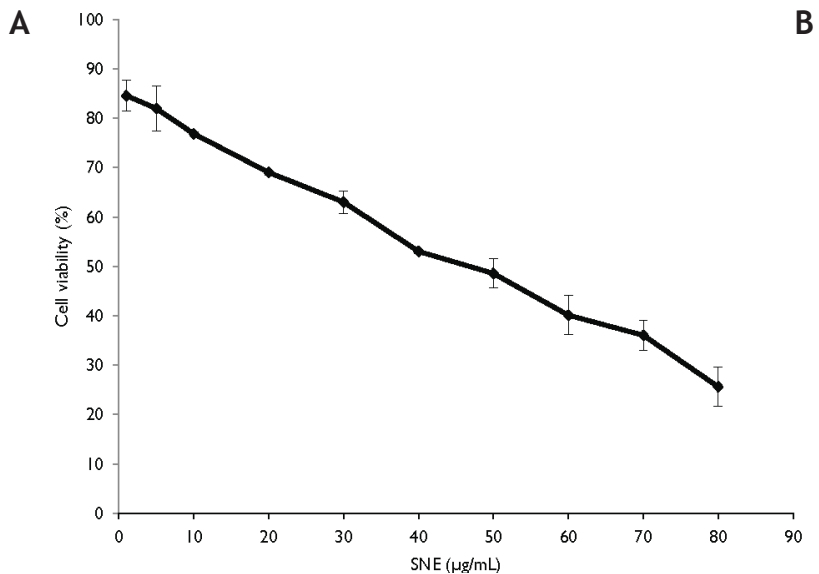

potency of SNE in combination treatment with DOX.

\section{Statistic}

All experiments were independently repeated at least three times. Student's t-test determined statistical significance for single and combination cytotoxicity.

\section{Apoptosis Assay}

The $5 \times 10^{3}$ cells were platted on coverslip and treated with SNE and DOX for $15 \mathrm{~h}$. At the end of incubation, cells were washed PBS and were added $10 \mu \mathrm{L}$ of ethidium bromide-acridine orange

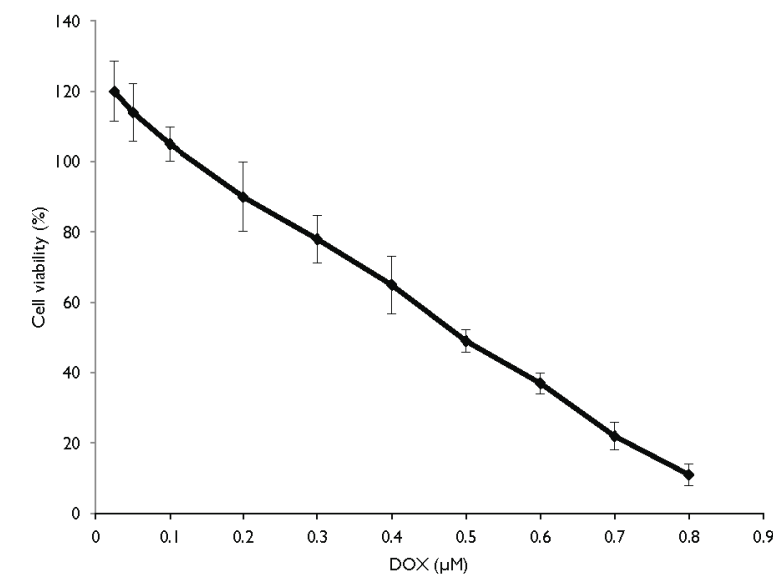

Figure 1. Single Cytotoxic Effect of SNE and DOX on MCF-7 Cells. (A) Treatment SNE (1-80 $\mu \mathrm{g} / \mathrm{mL})$ on MCF7 and $(B)$ treatment DOX $(0.25-0.8 \mu \mathrm{M})$ on MCF-7 cell for $24 \mathrm{~h}$ was measured using MTT assay. Data are represented as mean $-/+\mathrm{SE}$.

reagent (Sigma, USA) $5 \mu \mathrm{g} / \mathrm{mL}$ each coverslip. Cells were observed under a fluorescent microscope. Viable cells had green fluorescence, and apoptotic cells (early and late0.) had orange fluorescence with showing apoptotic bodies.

\section{RESULTS}

\section{Cytotoxic Effect of SNE and DOX on MCF-7 Cells}

Firstly, we investigate SNE and DOX's cytotoxic activity on MCF-7 breast cancer cells by
MTT assay. Single cytotoxicity assay of SNE was done in various concentrations on MCF-7 cells. SNE showed a cytotoxic effect in a dose-dependent manner with $\mathrm{IC}_{50}$ value of SNE was $50 \mu \mathrm{g} / \mathrm{mL}$ (Figure 1A). The results suggest that SNE induced toxicity on breast cancer cells.

\section{Synergistic Effect of Combination Treatment SNE and DOX on MCF-7 Cells}

Next, we generated the ability of SNE in combination with the chemotherapy agent, DOX. Based on previous research, DOX showed a cyto- 
A

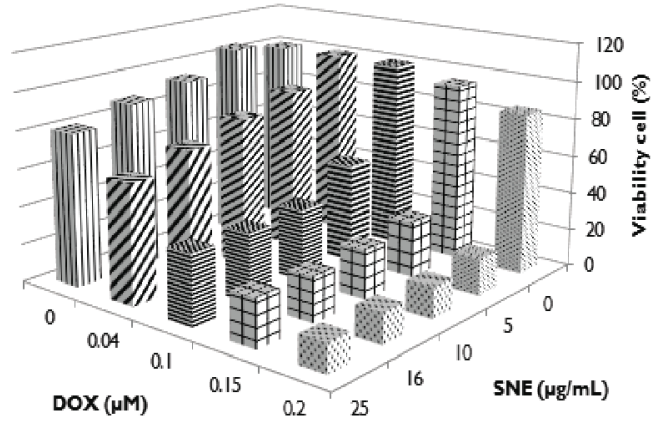

B

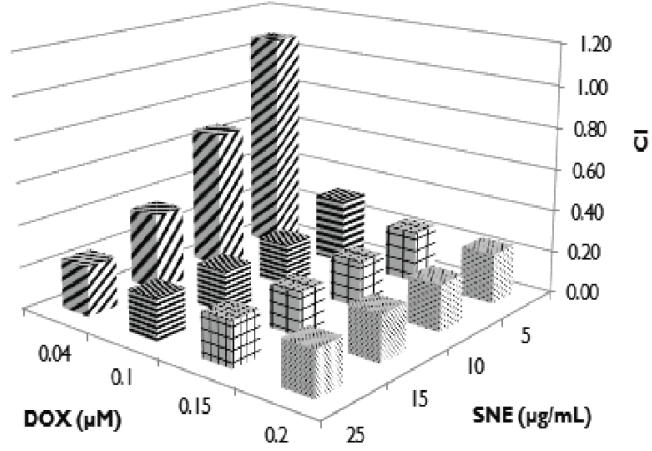

C

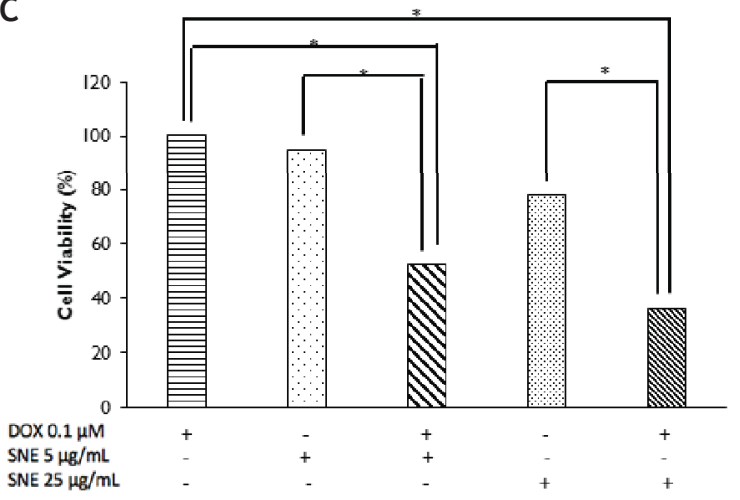

Figure 2. Combination Cytotoxic Effect of SNE and DOX on MCF-7 Cells. (A) The viability cells of combination treatment SNE with DOX on MCF-7 for $24 \mathrm{~h}$ was measured using MTT assay and (B) The $\mathrm{Cl}$ value of combination treatment SNE-DOX. (C) The viability cells of SNE (5 and $25 \mu \mathrm{g} / \mathrm{mL})$ with DOX $(0.1 \mu \mathrm{M})$. Data are represented as mean $-/+$ SE. $p<0.05$ (Student's t-test).

toxic effect with $\mathrm{IC}_{50} 400 \mathrm{nM}$ or $0.4 \mu \mathrm{M}$. We investigated the cytotoxic of DOX and showed with $\mathrm{IC}_{50} 0.5 \mu \mathrm{M}$ (Figure 1B). We therefore investigate the combination effect of SNE with DOX. The results showed that combination SNE and DOX with several doses (under $\mathrm{IC}_{50}$ ). Treatment of SNE and DOX on MCF-7 cells was conducted to investigate the ability of SNE to increase DOX's cytotoxicity on MCF-7 cells. The combination of SNE and DOX decreased cell viability rather than DOX solely (Figure 2, Tabel 1). The CI was calculated to evaluate the synergistic effect of the combination. According to the CI values as described by Reynolds and Maurer (2005), all of the tested combinations gave a synergistic effect, and some of them are strong synergist (Table 2). This result indicates that a combination of SNE and Dox is a more effective treatment than a single DOX treatment.

\section{Combination SNE and DOX Induce Apoptosis Incidence of MCF-7 Cells}

The synergetic effect combination of SNE and DOX showed in decreasing of viability cells. To understand the possible mechanism, we investigated the apoptosis incidence in combination treatment SNE and DOX. The Determination of apoptosis was carried under microscope fluorescence. The acridine orange permeates into nucleus and produces the green color. The Ethidium Bromide was taken up by the cell with losing the integrity of cytoplasmic membrane. SNE and DOX treatment showed apoptosis, and combination treatment increasing apoptosis events (Figure 3). The result suggest that SNE possibilities to increase the potency of apoptosis cells combined with DOX on breast cancer cells though the quantity of apoptotic event should be done. 
Indonesian Journal of Cancer Chemoprevention, June 2021

Tabel 1. Cell viability of combination treated, DOX and SNE.

\begin{tabular}{lcccccc}
\hline \multicolumn{2}{c}{ Cell viability $(\%)$} & \multicolumn{5}{c}{ DOX $(\mu \mathrm{M})$} \\
\cline { 2 - 6 } & & $\mathbf{0}$ & $\mathbf{0 . 0 4}$ & $\mathbf{0 . 1}$ & $\mathbf{0 . 1 5}$ & $\mathbf{0 . 2}$ \\
\hline \multirow{3}{*}{$\mathrm{SNE}$} & $\mathbf{0}$ & 100.00 & 100.25 & 99.76 & 94.35 & 85.20 \\
$(\mu \mathrm{g} / \mathrm{mL})$ & $\mathbf{5}$ & 94.92 & 86.43 & 52.30 & 29.44 & 19.05 \\
& 10 & 93.41 & 78.73 & 37.54 & 25.40 & 16.11 \\
& $\mathbf{1 6}$ & 88.25 & 70.71 & 35.95 & 23.02 & 16.03 \\
& $\mathbf{2 5}$ & 78.13 & 62.78 & 36.51 & 24.84 & 14.76 \\
\hline
\end{tabular}

\section{DISCUSSION}

Cytotoxic effect of leunca aginst cancer cell has been reported before. Leunca (Solanum nigrum L.) has been known to have cytotoxic effect against on several cancer cells (Sarmoko, et al., 2011; Maruti, et al., 2011; Moglad, 2018; Churiyah, et al., 2020). SNE was found to have low genotoxicity activity and acute toxicity on mice (Rumiyati, et al., 2015). This study investigated the cytotoxic of SNE on MCF-7 cells (Figure 1), with $\mathrm{IC}_{50} 50 \mu \mathrm{g} / \mathrm{mL}$. The SNE showed high toxicity on MCF-7 cells compared to HeLa cervical cancer cells and WiDr colon cancer cells. This finding indicated that SNE had cytotoxic potency towards MCF-7 cells.

We investigated the cytotoxic of DOX and used it for reference of combination with SNE. Based on previous research, a combination of leunca with several chemotherapy agents has been known to increases the cytotoxic of chemotherapy agents in several cancer cells (Sarmoko, et al., 2011; Istiaji, et al., 2010; Maruti, et al., 2011; Anindyajati, et al., 2010). The combination of SNE with DOX increased the cytotoxicity of DOX, reduced the cell viability and proliferation of $\mathrm{MCF}-7$ cells. The combination of SNE and DOX showed synergistic mechanism. The lowest concentration of SNE-DOX showed antagonism mechanism. The synergistic effect of SNE-DOX showed consistency with the results in the amount of cell viability. This result suggests that combination SNE-DOX possibility to induce apoptosis on MCF-7 cells.

We investigate the apoptosis event of a combination of SNE and DOX used Immunofluorescence Ethidium Bromide-Acridine orange assay. The apoptosis showed an orange color in cells and fragmentation body of cells. The single treatment of SNE and DOX showed inducing apoptosis, and interestingly, the combination of SNE-DOX more induces the evidence of apoptosis (Figure 3) although molecular mechanism should to be investigate. The synergistic mechanism of the reducing cell viability on the combination of SNE-DOX possibility induce apoptosis mechanism while the protein that responsibility the apoptosis should be explored. This result finds that the combination of SNE-DOX increases the sensitivity of DOX.

\section{CONCLUSION}

The SNE showed cytotoxic activity on MCF-7 breast cancer cells and induces the sensitivity the cells upon DOX treatment. The combina-

Tabel 2. Combination Index value of combination treatment DOX and SNE.

\begin{tabular}{lccccc}
\hline \multirow{2}{*}{ Cl } & & \multicolumn{4}{c}{ DOX concentration $(\mu \mathrm{M})$} \\
\cline { 3 - 5 } & & $\mathbf{0 . 0 4}$ & $\mathbf{0 . 1}$ & $\mathbf{0 . 1 5}$ & $\mathbf{0 . 2}$ \\
\hline SNE $(\mu \mathrm{g} / \mathrm{mL})$ & $\mathbf{5}$ & 1.07 & 0.31 & 0.24 & 0.24 \\
& $\mathbf{1 0}$ & 0.67 & 0.20 & 0.21 & 0.22 \\
& $\mathbf{I 5}$ & 0.36 & 0.19 & 0.20 & 0.22 \\
& $\mathbf{2 5}$ & 0.23 & 0.20 & 0.21 & 0.21 \\
\hline
\end{tabular}




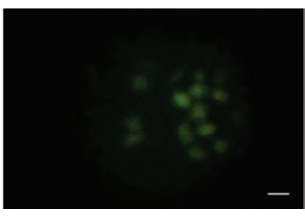

A

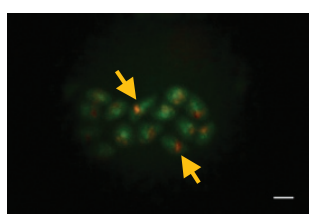

B

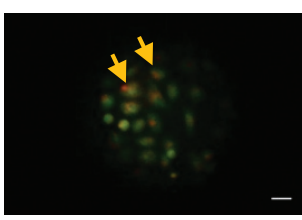

C

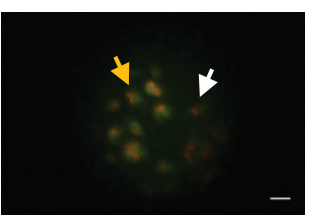

D

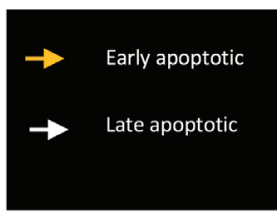

Figure 3. Apoptosis of SNE and DOX on MCF-7 Cells. Cell treated with SNE and DOX for $15 \mathrm{~h}$. (A) untreated,

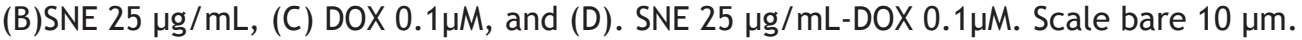

tion of SNE with chemotherapy agents decreases the usage concentration of DOX in this research, reduces the use of high concentration for doxorubicin as cancer therapy in vitro assay. So this data can be used to explore the prospect of SNE to reduce chemotherapy agent resistance evidence but it needs to explore more. The combination of SNEDOX-induced the apoptosis mechanism and needs to be explored further about the protein of apoptosis that responsible for inducing apoptosis.

\section{ACKNOWLEDGMENT}

We thank Cancer Chemoprevention Research Center, Faculty of Pharmacy, Universitas Gadjah Mada for funding this research.

\section{REFERENCES}

Anindyajati, A., Sarmoko, S., Putri, D.D.P., Hermawan, A. and Meiyanto, E., 2010, Combination of Solanum nigrum L. herb ethanolic extract and doxorubicin performs synergism on T47D breast cancer cells, Indonesian Journal of Cancer Chemoprevention, 1(2), 78-84.

Ansari, L., Shiehzadeh, F., Taherzadeh, Z., Nikoofal-Sahlabadi, S., Momtazi-Borojeni, A.A., Sahebkar, A. and Eslami, S., 2017, The most prevalent side effects of pegylated liposomal doxorubicin monotherapy in women with metastatic breast cancer: a systematic review of clinical trials, Cancer gene therapy, 24(5), 189-193.

Butt, G., Romero, M.A., Tahir, F. and Farooqi,
A.A., 2018, Emerging themes of regulation of oncogenic proteins by Solanum nigrum and its bioactive molecules in different cancers, Journal of cellular biochemistry, 119(12), 9640-9644.

Churiyah, C., Ningsih, S. and Firdayani, F., 2020, The Cytotoxic, Apoptotic Induction, and Cell Cycle Arrest Activities of Solanum nigrum L. Ethanolic Extract on MCF-7 Human Breast Cancer Cell, Asian Pacific Journal of Cancer Prevention, 21(12), 3735-3741.

Cooper, G.M. and Hausman, R.E., 2000, The development and causes of cancer, The cell: A molecular approach, 2.

Elbehairi, S.E.I., Al-Abbasi, F.A., Mohamed, A.F., Mohamed, N.G., Basuony, M.I., Salem, M.M., Montaser, M.M., Alfaifi, M.Y., Eid, S.Y. and Al-Abd, A.M., 2020, Mathematical analysis for the combinatorial cytotoxic properties of the standardized extract of Annona cherimola or Solanum nigrum with 5-FU against head and neck cancer cells. Proceeding: AACR Annual Meeting, 80(16).

Franco, Y.L., Vaidya, T.R. and Ait-Oudhia, S., 2018, Anticancer and cardio-protective effects of liposomal doxorubicin in the treatment of breast cancer, Breast Cancer: Targets and Therapy, 10, 131.

Heer, E., Harper, A., Escandor, N., Sung, H., McCormack, V. and Fidler-Benaoudia, M.M., 2020, Global burden and trends in premenopausal and postmenopausal breast cancer: a population-based study, The Lancet Global Health, 8(8), e1027-e1037. 
Indonesian Journal of Cancer Chemoprevention, June 2021 ISSN: 2088-0197

e-ISSN: $2355-8989$

Istiaji, R.P., Fitria, M., Larasati, L., Tjondro, F., Maruti, A.A., Setyowati, E.P., and Meiyanto, E., 2010. Leunca (Solanum nigrum L.) Herbs Ethanolic Extract Increase Cytotoxic Activity of Cisplatin on Hela Cervical Cancer Cells, Indonesian Journal of Cancer Chemoprevention, 1(1), 32-37.

Lankelma, J., Dekker, H., Luque, R.F., Luykx, S., Hoekman, K., Van Der Valk, P., Van Diest, P.J. and Pinedo, H.M., 1999, Doxorubicin gradients in human breast cancer, Clinical cancer research, 5(7), 1703-1707.

Ling, B., Xiao, S., Yang, J., Wei, Y., Sakharkar, M.K. and Yang, J., 2019, Probing the Antitumor Mechanism of Solanum nigrum L. Aqueous Extract against Human Breast Cancer MCF7 Cells, Bioengineering, 6(4), 112.

Maruti, A.A., Putri, D.D.P. and Hermawan, A., 2011, The Cytotoxic activity of Solanum nigrum ethanolic extract on widr human colon cancer cells, Indonesian Journal of Cancer Chemoprevention, 2(3), 291-294.

Moglad, E.H., 2019, Ethyl acetate fraction of Solanum nigrum L.: Cytotoxicity, induction of apoptosis, cell cycle in breast cancer cells, and gas chromatography-mass spectrometry analysis, Asian Journal of Pharmaceutics, 13(3).

Momenimovahed, Z. and Salehiniya, H., 2019, Epidemiological characteristics of and risk factors for breast cancer in the world, Breast Cancer: Targets and Therapy, 11, 151.

Reynolds, C.P. and Maurer B.J., 2005, Evaluating Response to Antineoplastic Drug Combinations in Tissue Culture Models, Methods in Molecular Medicine, 110, 173-183.

Rumiyati, R., Muna, L.N., Hidayati, D.N. and Jenie, R.I., 2015, Acute toxicity and genotoxic activity of leunca (Solanum nigrum L.) herb ethanolic extract, Indonesian Journal of Cancer Chemoprevention, 6(1), 30-34.

Sarmoko, S., Putri, D.D.P., Puspitasari, E., Anindyajati, A. and Meiyanto, E., 2011, Combination of Leunca Herb Ethanolic Extract and Doxorubicin Suppresses HeLa Cells' Growth, Indonesian Journal of Cancer Chemoprevention, 2(3), 281-285.

Shirkavad, A., Borojeni, Z.N. and Aleyasin, S.E., 2019, Methanol Extract of Solanum nigrum Induces Autophagy and Apoptosis in MDAMB-468 Breast Cancer Cells, Indian Journal of Pharmaceutical Sciences, 81(3), 527-532.

Ulaner, G.A., Riedl, C.C., Dickler, M.N., Jhaveri, K., Pandit-Taskar, N. and Weber, W., 2016, Molecular imaging of biomarkers in breast cancer, Journal of nuclear medicine: official publication, Society of Nuclear Medicine, 57(Suppl 1), $53 \mathrm{~S}$.

Waks, A.G. and Winer, E.P., 2019, Breast cancer treatment: a review, Jama, 321(3), 288-300.

Wang, Q., Jiang, J., Ying, G., Xie, X.Q., Zhang, X., Xu, W., Zhang, X., Song, E., Bu, H., Ping, Y.F. and Yao, X.H., 2018, Tamoxifen enhances stemness and promotes metastasis of ERa36+ breast cancer by upregulating ALDH1A1 in cancer cells, Cell research, 28(3), 336-358. 